\title{
Covid-19: A New Cause for Taste and Smell Dysfunction
}

\author{
Iqbal Hussain Udaipurwala
}

How to cite this Article:

Udaipurwala IH. Covid-19: A New Cause for Taste and Smell Dysfunction. J Bahria Uni Med Dental Coll. 2020;11(4):142-143 DOI: https://doi.org/10.51985/JBUMDC2021071

This is an Open Access article distributed under the terms of the Creative Commons Attribution Non Commercial License (http:// creativecommons/org/licences/by-nc/4.0) which permits unrestricted non commercial use, distribution and reproduction in any medium, provided the original work is properly cited.

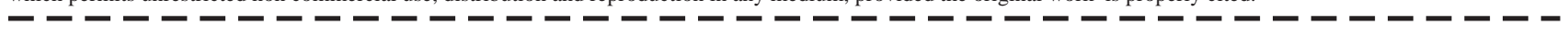

Dysfunction of the sense of smell and taste may have severe impact on quality of life and overall health. Detection of bad smell in the local environment is a warning sign for a person and a good smell is pleasurable in life. Similarly sense of taste is also very important for pleasure and to avoid intake of hazardous meal or drink. Unfortunately, knowledge about the smell and taste dysfunction is very limited and little work has been conducted in this field. There is a long list of disorders and diseases that can affect and disturb olfactory and gustatory functions, ranging from the local to central neurological causes. Virtually any disease of the nose or paranasal sinuses can cause hyposmia or anosmia, the common being chronic rhino-sinusitis, atrophic rhinitis, nasal polypi, allergic rhinitis or neoplasia. The neurological causes may include any pathology that can affect olfactory nerves, olfactory bulb and their central connections or the primary olfactory cortex. A new cause in the list is COVID-19 infection for which medical fraternity is thriving hard to unveil the underlying mechanisms responsible for producing features.

With the recent pandemic of COVID-19, there is an explosion of patients in hospitals with varied symptoms from just fever to multiple organ failure. ${ }^{1}$ A typical case of COVID-19 presents with fever and dry cough which may progress to pneumonia. ${ }^{2}$ Majority of the symptoms are related with the upper or lower respiratory tract involvement by the virus. Various studies have been published emphasizing about new and atypical symptoms of COVID-19 related with taste and smell dysfunction. ${ }^{3,4}$ The incidence of olfactory dysfunction have been reported in viral infections like rhinovirus, parainfluenza virus, Epstein-Barr virus and corona virus in the past as well. ${ }^{5,6}$ Though in COVID-19 patients, this smell dysfunction is not related with nasal obstruction and nasal discharge. Cases have been recorded where isolated taste and smell loss is present with no other symptom of COVID19 like fever, rhinorrhoea, body ache, breathlessness or cough etc. ${ }^{7}$

The objective assessment of olfactory and gustatory functions are not routinely performed in general health/medical

Iqbal Hussain Udaipurwala
Professor, Department of ENT
Bahria University Medical and Dental College, Karachi
Received: 28-Sep-2021 |
Accepted: 08-Oct-2021

checkup. The clinicians and physicians rely only on selfreporting of the symptom. Many of the patients are even unaware of any dysfunction present in these two special senses. According to one study from Europe, the olfactory and taste dysfunction occurrence in COVID-19 patients is around $85.6 \%$ and $88.8 \%$ respectively. ${ }^{8}$ A local study from Pakistan showed association of anosmia in $43.75 \%$ and ageusia in $31.25 \% .{ }^{9}$ In addition, these smell and taste dysfunction may appear before, during or even after development of other typical symptoms of COVID-19. The present data depicts that the incidence of these two symptoms in European patients is much higher than the rest of the world. As taste and smell loss can be the only and early symptom of COVID-19, it should bear in mind when considering differential diagnosis in such situation. The time period for recovering from these two symptoms also varied from days to weeks to months even after improving all other symptoms. ${ }^{8}$

The fundamental pathophysiological mechanism for smell and taste dysfunction among COVID-19 patients is still unclear. It is not only related with nasal, oral and olfactory mucosa rather there is involvement of nerves and central nervous system. The viruses are known to effect nerves and central nervous system. The neurological involvement in COVID-19 patients, is broadly classified into symptoms related with the central nervous system and peripheral nervous system. The central nervous system manifestation may include, dizziness, headache, altered consciousness, epilepsy and acute cerebrovascular lesions. The peripheral nervous system manifestations are anosmia, hyposmia, ageusia, hypogeusia, muscular pain and muscle weakness. ${ }^{10}$ In animal studies, it has been suggested that SARS-CoV (human angiotensin converting enzyme 2) may go into the central nervous tissues through the olfactory bulb. ${ }^{11}$ Neurological involvement may occur in about $35 \%$ of all COVID-19 patients which may be much higher in patients with severe symptoms. The objective assessment of the smell and taste function through some objective tests are lacking, mainly because of the risk of disease transmission in current pandemic. With proper training and teaching, some of the objective tests like smell identification with UPSIT and chemical gustometry to differentiate taste can be done through telemedicine or through video consultation. Secondly with proper protective measures clinical examination, nasal endoscopy, electrophysiological tests for 
smell and taste and laboratory tests can be performed safely to further investigate about etiology, pathophysiology and outcome in these patients.

As far as treatment of smell and taste dysfunction is concerned, there is no specific therapy for it. Use of corticosteroid either systemic or intranasal is also of doubtful value. It may be used to reduce inflammation in the nervous tissue but in turn it can flare up the primary viral infection. Olfactory training is another approach to improve smell dysfunction after COVID-19 infection. A neuroprotective treatment and approaches that can check the invasion of SARS-CoV-2 to the central nervous system are next needed tactics in our fight against COVID-19. ${ }^{12}$

In conclusion, involvement of smell and taste function in COVID-19 may occur in many patients. There is a wide range in incidence from $5 \%$ to $98 \%$ depending upon the different methodology utilized in geographical region focused in the study. Considering all above facts and figures, following are the suggestions or possible solutions to physicians such as otorhinolaryngologists, pulmonologists who are dealing with COVID-19 patients baring taste and smell dysfunctions.

1. Advise for isolation and further investigations even if the patient presents with symptoms of taste and smell dysfunction only.

2. Reassure the patient as symptoms are likely to be resolved but recovery period varies greatly.

3. Brief the patient about association of COVID-19 virus with different mutations and clinical manifestations

4. Formulate a multidisciplinary team comprised of general physician, otolaryngologist, pulmonologist, pathologist, microbiologist etc for quality treatment and management of patients.

5. Conduct detailed studies with examination/endoscopic findings, psychophysiological tests and electrophysiological tests of olfactory and gustatory functions.

Authors Contribution:

Iqbal Hussain Udaipurwala: Substantial contributions to the

I conception criticaly evaluation of intellectual content, final

| approval of the version to be published

ᄂ ---------------

\section{REFERENCES}

1. Lee Y, Min P, Lee S, Kim SW. Prevalence and duration of acute loss of smell and taste in COVID-19 patients. J Korean Med Sci. 2020; 35(18): e174. DOI: https://doi.org/10.3346/ jkms.2020.35.e174.
2. Yang X, Yu Y, Xu J, Shu H, Xia J, Liu H, et al. Clinical course and outcomes of critically ill patients with SARS-CoV-2 pneumonia in Wuhan, China: a single-centered, retrospective, observational study. Lancet Respir Med 2020; 8(5): S22132600(20)30079-5.

3. Mullol J, Alobid I, Mariño-Sánchez F, Izquierdo-Domínguez A, Marin C, Klimek Let al. The Loss of Smell and Taste in the COVID-19 Outbreak: a Tale of Many Countries. Curr Allergy Asthma Rep. 2020; 20(10): 61. DOI: https://doi.org/ 10.1007/s11882-020-00961-1.

4. Vaira LA, Salzano G, Fois AG, Piombino P, De Riu G. Potential pathogenesis of ageusia and anosmia in COVID-19 patients. Int Forum Allergy Rhinol. 2020; 10(9): 1103-1104. doi: 10.1002/alr.22593.

5. Suzuki M, Saito K, Min WP, Vladau C, Toida K, Itoh H et al. Identification of viruses in patients with post-viral olfactory dysfunction. Laryngoscope 2007; 117(2): 272-277

6. Van Riel D, Verdijk R, Kuiken T. The olfactory nerve: a shortcut for influenza and other viral diseases into the central nervous system. J Pathol. 2015; 235(2):277-287. DOI: https://doi.org/10.1002/path.446

7. Hjelmesæth J, Skaare D. Loss of smell or taste as the only symptom of COVID-19. Tidsskr Nor Laegeforen. 2020; 140(7). DOI: https://doi.org/10.4045/tidsskr.20.0287.

8. Lechien JR, Chiesa-Estomba CM, De Siati DR, Horoi M, Le Bon SD, Rodriguez A, et al. Olfactory and gustatory dysfunctions as a clinical presentation of mild-to-moderate forms of the coronavirus disease (COVID-19): a multicenter European study. Eur Arch Otorhinolaryngol. 2020; 277(8): 2251-2261. DOI: https://doi.org/10.1007/s00405-020-059651.

9. Iqbal M, Khan SW, Khan S, Ahmad W. Prevalence of Anosmia \& Ageusia in confirmed COVID-19 patients at teaching hospitals of District Bannu and Swat, Pakistan. Int J Endorsing Health Sci Res. 2021; 9(2): 217-22. DOI: https://doi.org/ 10.29052 /IJEHSR. v9.i2.2021.217-222

10. Koyuncu OO, Hogue IB, Enquist LW. Virus infections in the nervous system. Cell Host Microbe, 2013; 13(4): 379-393. DOI: https://doi.org/10.1016/j.chom.2013.03.010

11. Netland J, Meyerholz DK, Moore S, Cassell M, Perlman S. Severe acute respiratory syndrome coronavirus infection causes neuronal death in the absence of encephalitis in mice transgenic for human ACE2. J Virol, 2008; 82(15): 7264-7275. DOI: https://doi.org/10.1128/JVI.00737 -08

12. Baig AM, Wasay M. Covid-19 infection; loss of taste, smell, and neurogenic respiratory failure. Pak J Neurological Sci., 2020; 15(1): 1-2.

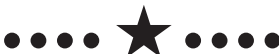

